\title{
High frequency oscillatory ventilation in leptospirosis pulmonary hemorrhage syndrome: A case series study
}

\author{
Mohd Basri Mat Nor, Azrina Md Ralib, Noor Airini Ibrahim¹, Mohd Rasydan Abdul-Ghani
}

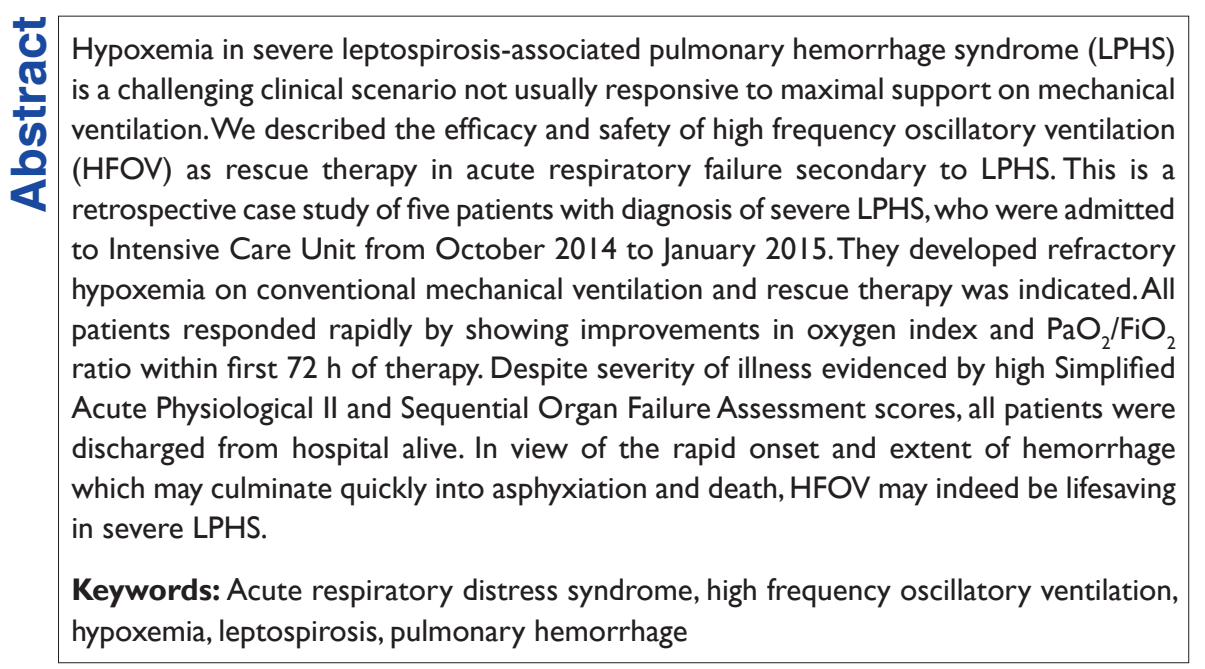

\begin{tabular}{|l|}
\hline Access this article online \\
\hline Website: www.ijccm.org \\
\hline DOI: 10.4103/0972-5229.183906 \\
\hline Quick Response Code: \\
\hline
\end{tabular}

\section{Introduction}

Leptospirosis, a zoonotic infection, is an acute febrile illness caused by pathogenic spirochetes of the genus Leptospira. Generally, there are two types of infection that portray different signs and symptoms, which are anicteric and icteric leptospirosis. Ninety percent of cases are anicteric, which means that jaundice does not occur. The clinical course of leptospirosis is variable. It has inconsistent clinical manifestations which range from mild disease to severe form, classically presenting as triad of Weil, i.e. fever, jaundice, and acute kidney injury $(\mathrm{AKI}) \cdot{ }^{[1,2]}$ Weil syndrome primarily manifests as profound

\section{From:}

Department of Anaesthesiology and Intensive Care, Kulliyyah of Medicine, International Islamic University Malaysia, Jalan Hospital Campus, 25100

Kuantan, Pahang, 'Department of Surgery, Anaesthesiology Unit, Faculty of

Medicine and Health Sciences, University Putra Malaysia, Serdang,

43400 Selangor, Malaysia

\section{Correspondence:}

Dr. Mohd Basri Mat Nor, Department of Anaesthesiology and Intensive Care, Kulliyyah of Medicine, International Islamic University Malaysia, Jalan Hospital Campus, 25100 Kuantan, Pahang, Malaysia.

E-mail: basri.matnor@gmail.com jaundice, renal dysfunction, hepatic necrosis, pulmonary dysfunction, and hemorrhagic diathesis. The icteric phase is much more severe than the anicteric one and may develop into a more fatal condition. Other complications include rhabdomyolysis, myocarditis, and uveitis. Weil syndrome with hepatorenal involvement and jaundice has a mortality rate of $20-40 \%$. Pulmonary manifestations occur in $20-70 \%$ of leptospirosis patients but are often overshadowed by other symptoms. Lung involvement may vary from subtle clinical features to acute respiratory distress syndrome (ARDS) and deadly leptospirosis-associated pulmonary hemorrhage syndrome (LPHS). ${ }^{[3,4]}$

This is an open access article distributed under the terms of the Creative Commons Attribution-NonCommercial-ShareAlike 3.0 License, which allows others to remix, tweak, and build upon the work non-commercially, as long as the author is credited and the new creations are licensed under the identical terms.

For reprints contact: reprints@ medknow.com

How to cite this article: Mat Nor MB, Md Ralib A, Ibrahim NA, Abdul-Ghani MR. High frequency oscillatory ventilation in leptospirosis pulmonary hemorrhage syndrome: A case series study. Indian J Crit Care Med 2016;20:342-8. 
Leptospirosis is distributed worldwide, with majority of cases occurring in impoverished populations inhabiting developing countries with tropical climates. In a recent study by Costa et al., leptospirosis was estimated to cause more than 1 million severe cases and approximately 60,000 deaths each year. ${ }^{[5]}$ Therefore, it has emerged as a leading zoonotic cause of morbidity and accounts for numbers of deaths, which approach or exceed those for other causes of hemorrhagic fever. In the last two decades, there are an increasing number of LPHS cases in patients with severe pulmonary involvement. Segura et al. reported 321 cases with serologic and clinical evidence of leptospirosis in Peru, 189 were from urban location and 132 from rural areas. Seven patients (3.7\%) with a history of urban exposure had severe pulmonary manifestations; of these, five patients died; four deaths were caused by severe pulmonary hemorrhage, and one was caused by ARDS and multiorgan failure. ${ }^{[6]}$ In a 12-month study, pulmonary hemorrhage occurred in 14 of 75 patients (19\%) admitted to hospital with leptospirosis in Seychelles, causing deaths of six patients $(8 \%) \cdot{ }^{[7]}$ However, the incidence of LPHS in Malaysian population is unknown. According to data from Ministry of Health Malaysia, the annual incidence rate of leptospirosis has increased dramatically from 6.99 to 25.94 cases per 100,000 populations from 2010 to 2014 . The mortality rate has also increased from 0.24 to 0.31 per 100,000 populations over the last 10 years. ${ }^{[8]}$

Gross pathology of the lung in severe pulmonary form of leptospirosis generally shows extensive pulmonary hemorrhage, with numerous bleeding foci of different sizes. Histological sections usually reveal pulmonary congestion, pulmonary edema, and several foci of interstitial and intra-alveolar bleeding. ${ }^{[9]}$ In a recent study by Croda et al., it was found that the linear deposition of immunoglobulins (IgA, IgG, and IgM), and complement on the alveolar surface may play a role in the pathogenesis of pulmonary hemorrhage in LPHS. ${ }^{[10]}$ This is due to a toxin-mediated process which induces vascular injury, particularly a small vessel vasculitis. There is remarkable leakage of fluid and proteins into intravascular space with extrusion of erythrocytes culminating into widespread hemorrhagic infiltrates. Electron microscopy finds damage into capillaries as the primary lesion. Endothelial cells swell and detach from the basement membrane leaving areas of exposed interstitium, even in areas free of hemorrhage. ${ }^{[3,11]}$

A high index of suspicion is required to make the diagnosis based on epidemiologic exposure and clinical manifestations. As the clinical features are nonspecific, leptospirosis can be confirmed only by laboratory tests.
Microscopic agglutination test is a reference standard but not readily available. A number of simple rapid tests such as IgM ELISA and macroscopic slide agglutination test have been developed; however, these tests become positive only after a week. The organism can be cultured, but this may take several weeks. Therefore, definitive guidelines for the diagnosis of human leptospirosis are necessary such as the modified Faine's criteria with amendment (2012) from the original WHO guidelines 1982. ${ }^{[12]}$ In these guidelines, the diagnosis is based on three categories, i.e., clinical data (Part A), epidemiological factors (Part B), and bacteriological and lab findings (Part C). In the first week, clinical and epidemiological factors $(A+B)$ are of value, whereas in the $2^{\text {nd }}$ week, laboratory tests should be used to confirm diagnosis. When available, polymerase chain reaction can be used as a diagnostic tool in the $1^{\text {st }}$ week. In the recent 2012 guidelines, hemoptysis and dyspnea were included in the clinical criteria as pulmonary hemorrhage is recognized as an important complication. Presumptive diagnosis of leptospirosis is made based on scoring when Part $(A+B+C)$ is 25 or more. In the $1^{\text {st }}$ week when laboratory tests are not available, a score of 26 or more for Part $(\mathrm{A}+\mathrm{B})$ is diagnostic. The $(\mathrm{A}+\mathrm{B})$ criteria should be used to start empiric therapy even for possible leptospirosis $(A+B=20-25)$.

Severe LPHS is a serious complication of leptospirosis and has reported mortality rates of up to $75 \%$ even when optimal treatment is provided. ${ }^{[3,13]}$ Accumulation of hemorrhagic fluid in the alveoli may result in airway obstruction and ventilation-perfusion mismatch with acute gas exchange failure. In this situation, hypoxemia in LPHS may be difficult to treat in spite of timely initiation of conventional mechanical ventilation (CMV). Data on the use of high frequency oscillatory ventilation (HFOV) for this disease are scarce in the literature. We report our experience with HFOV as rescue therapy in patients with massive pulmonary hemorrhage who deteriorated on CMV.

\section{Case Report}

This is a retrospective case series, reviewed from patient records in a tertiary adult Intensive Care Unit (ICU) in Pahang, Malaysia. All five patients were admitted to ICU in between October 2014 and January 2015, which is within Northeast monsoon season that brings more rainfall compared to other months. Publication of patients' data, informed consent, and anonymity requirements is in agreement with the rules of the Ethical Committee of our institution. All leptospirosis patients with pulmonary hemorrhage were initially 
ventilated with either bilevel positive airway pressure control ventilation or volume control ventilation. HFOV (SensorMedics 3100B, Yorba Linda, CA, USA) was started as rescue therapy for ARDS when there was severe hypoxemia $\left(\mathrm{PaO}_{2} / \mathrm{FiO}_{2}<100 \mathrm{mmHg}\right.$, arterial saturation $\mathrm{SaO}_{2}<90 \%$ ) with or without ventilation failure $(\mathrm{pH}<7.25)$ and plateau airway pressure $\geq 30 \mathrm{cmH}_{2} \mathrm{O}$. Oxygen index (OI) was calculated using formula; $100 \times \mathrm{mPaw} \times \mathrm{FiO}_{2} / \mathrm{PaO}_{2}$. Mean airway pressure $(\mathrm{mPaw})$ was initially set as $5 \mathrm{cmH}_{2} \mathrm{O}$ above plateau pressure (plateau P) on CMV but not exceeding $40 \mathrm{cmH}_{2} \mathrm{O}$. All patients were adequately volume resuscitated and had mean arterial pressure (MAP) $\geq 65 \mathrm{mmHg}$ with or without continuous infusion of vasoactive agents before transition to HFOV. Recruitment maneuver was performed with mPaw of $40 \mathrm{cmH}_{2} \mathrm{O}$ for $40 \mathrm{~s}$ with precautions and terminated immediately if associated with hypotension (MAP $<60 \mathrm{mmHg}$ or decrease by $>20 \mathrm{mmHg}$ ) or oxygen desaturation (decrease in oxygen saturation, $\mathrm{SpO}_{2}$ to $\leq 85 \%$, or decrease of more than $5 \%$ ). ${ }^{[14]}$ Results are presented as mean \pm standard deviation for normally distributed variables or median (interquartile range) for nonnormally distributed variables. Comparisons of oxygenation index, $\mathrm{PaO}_{2} / \mathrm{FiO}_{2}$, and $\mathrm{PaCO}_{2}$ over time were analyzed using the repeated measures analysis of variance (ANOVA). All nonnormally distributed variables were log-transformed before repeated measures ANOVA analysis.

Five patients who progressed to severe LPHS and treated with HFOV as rescue therapy were included in the study. Their main clinico-epidemiological and laboratory blood results are demonstrated in Tables 1 and 2, respectively. Four patients had clinico-epidemiological information in agreement with those observed in icteric leptospirosis and one suffered anicteric leptospirosis. Their hemoglobin levels dropped to below $10 \mathrm{~g} / \mathrm{dL}$ within $24 \mathrm{~h}$ or at the same day of ICU admission. All patients had high Sequential Organ Failure Assessment (SOFA) scores due to rapid progression to multiple organ dysfunction syndrome and septic shock. They required vasoactive drugs to maintain appropriate MAP $\geq 60 \mathrm{mmHg}$. All five patients had Stage $3 \mathrm{AKI}$ and were prescribed renal replacement therapy (RRT) within $24 \mathrm{~h}$ of ICU admission. Duration of HFOV and CMV, length of ICU and hospital stays, and in-hospital mortality are

\begin{tabular}{|c|c|c|c|c|c|}
\hline $\begin{array}{l}\text { Patient } \\
\text { number }\end{array}$ & $\begin{array}{l}\text { Age (years)/ } \\
\text { sex }\end{array}$ & Clinical and epidemiological information & $\begin{array}{l}\text { Faine's scores: } A+B \\
\text { and } A+B+C\end{array}$ & $\begin{array}{l}\text { Illness } \\
\text { duration } \\
\text { (days) }\end{array}$ & $\begin{array}{l}\text { Vasoactive agents before } \\
\text { transition to HFOV }\end{array}$ \\
\hline I & 54/female & $\begin{array}{l}\text { History of diabetes mellitus and hypertension. Fever, } \\
\text { headache, cough, chest pain, vomiting, acute respiratory } \\
\text { failure, acute shortness of breath, pulmonary hemorrhage, } \\
\text { ARDS, AKI (started on CVVH), and mixed respiratory and } \\
\text { metabolic acidosis. Admitted to ICU from DEM. Rapid } \\
\text { test was positive }\end{array}$ & 21 and 36 & 7 & Noradrenaline \\
\hline 2 & $62 /$ male & $\begin{array}{l}\text { Work as a cleaner and history of cleaning a pond at a } \\
\text { polytechnic college and active smoker, NKMI. Fever, } \\
\text { headache myalgia, arthralgia, acute shortness of breath, } \\
\text { diarrhea. Pulmonary hemorrhage, ARDS, AKI (started on } \\
\text { IHD), and severe metabolic acidosis. Admitted to ICU } \\
\text { after } 2 \text { days in acute medical ward. Rapid test was positive }\end{array}$ & 22 and 37 & 6 & Noradrenaline. \\
\hline 3 & $31 /$ male & $\begin{array}{l}\text { Cambodian with NKMI. History of fishing and } \\
\text { swimming at a waterfall. Fever, chills, rigors, headache, } \\
\text { arthralgia, myalgia, vomiting, diarrhea, hemoptysis, } \\
\text { pulmonary hemorrhage, ARDS, AKI (started on CVVH), } \\
\text { hyperkalemia, and mixed respiratory and metabolic } \\
\text { acidosis. Admitted to ICU after } 24 \text { hours in acute medical } \\
\text { ward. Rapid test was positive }\end{array}$ & 22 and 37 & 7 & Noradrenaline \\
\hline 4 & $36 /$ male & $\begin{array}{l}\text { Indonesian with NKMI. He works as a general laborer at } \\
\text { palm oil plantation. Fever, headache, chills, rigors, lethargy, } \\
\text { arthralgia, myalgia, abdominal pain, cough, pulmonary } \\
\text { hemorrhage, ARDS, AKI (started on IHD), and mixed } \\
\text { respiratory and metabolic acidosis. Admitted to ICU after } \\
2 \text { days in acute medical ward. Rapid test was positive }\end{array}$ & 21 and 36 & 5 & Noradrenaline, vasopressin \\
\hline 5 & $40 /$ male & $\begin{array}{l}\text { Cambodian with NKMI. He had recent traveling to } \\
\text { Cambodia I month before hospital admission. Fever, } \\
\text { headache, cough, hemoptysis, anemia, jaundice, ARDS, } \\
\text { AKI (started on CVVH), severe metabolic, and respiratory } \\
\text { acidosis. Admitted directly from DEM. Rapid test was } \\
\text { positive }\end{array}$ & 23 and 38 & 7 & Noradrenaline, adrenaline \\
\hline
\end{tabular}

AKI: Acute kidney injury; CWH: Continuous venovenous hemodialysis; IHD: Intermittent hemodialysis; NKMI: No known medical illness; Faine's score: Modified Faine's criteria with amendment (2012); Rapid test: IgM ELISA test; DEM: Department of Emergency Medicine; ARDS: Acute respiratory distress syndrome; HFOV: High frequency oscillatory ventilation 
shown in Table 3. Despite severity of illness evidenced by high Simplified Acute Physiological II and SOFA scores, all patients survived and were discharged from hospital alive.

Duration of patients on CMV before transition to HFOV is shown in Table 3. After omitting the time taken for transportation, the mean duration on CMV before changing to HFOV was $9.8 \mathrm{~h}$. The CMV values before transition are presented in Table 4 . They had mixed

Table 2: Summary of important laboratory data on the day of admission to Intensive Care Unit

\begin{tabular}{|c|c|c|c|c|c|c|}
\hline \multirow{2}{*}{$\begin{array}{l}\text { Laboratory } \\
\text { results }\end{array}$} & \multirow[t]{2}{*}{ Normal range } & \multicolumn{5}{|c|}{ Patient number } \\
\hline & & I & 2 & 3 & 4 & 5 \\
\hline Hemoglobin & $1 \mathrm{I}-\mathrm{I} 5 \mathrm{~g} / \mathrm{dL}$ & $8.7^{*}$ & $9.5^{*}$ & $6.0 *$ & 8.0 & $6.7^{*}$ \\
\hline White blood cell & $4-11 \times 10^{9} / \mathrm{L}$ & 18.8* & $15.8^{*}$ & $15.5^{*}$ & 9.6 & $34.6 *$ \\
\hline Platelets & $150-300 \times 10^{9} / \mathrm{L}$ & 178 & $17^{*}$ & $102 *$ & $63^{*}$ & $125 *$ \\
\hline Creatinine & $70-120 \mu \mathrm{mol} / \mathrm{L}$ & I73* & $396 *$ & $183 *$ & $585^{*}$ & $238 *$ \\
\hline Creatine kinase & $<160 \mathrm{U} / \mathrm{L}$ & 91 & $1118 *$ & $728 *$ & 1059* & $667 *$ \\
\hline Total bilirubin & $<20 \mu \mathrm{mol} / \mathrm{L}$ & 10.3 & $80.3^{*}$ & $52.3^{*}$ & $54.4^{*}$ & I76* \\
\hline $\mathrm{ALT}$ & $5-45 \mathrm{U} / \mathrm{L}$ & 23 & $53^{*}$ & 1477* & $81 *$ & |477* \\
\hline AST & I0-45 U/L & 34 & $95^{*}$ & $2580 *$ & $87^{*}$ & $3623 *$ \\
\hline ALP & $65-180 \mathrm{U} / \mathrm{L}$ & 70 & 173 & $286 *$ & 149 & 116 \\
\hline INR & $0.8-1.1$ & $1.2 *$ & I.I & $1.5^{*}$ & $1.4^{*}$ & $2.0 *$ \\
\hline APTT & $25-37 s$ & $44^{*}$ & $92.3 *$ & $140 *$ & $61.7 *$ & $43^{*}$ \\
\hline Lactate & $<2 \mathrm{mmol} / \mathrm{L}$ & $6.4^{*}$ & 2.0 & $7.9 *$ & I.I & $7.0^{*}$ \\
\hline
\end{tabular}

*Abnormal results. ALT: Alanine transaminase; AST: Aspartate aminotransferase; ALP: Alkaline phosphatase; INR: International Normalized Ratio; APTT: Activated partial thromboplastin time

Table 3: Patient characteristics and outcomes

\begin{tabular}{lccccc}
\hline Variables & \multicolumn{5}{c}{ Patients number } \\
\cline { 2 - 6 } & $\mathbf{1}$ & $\mathbf{2}$ & $\mathbf{3}$ & $\mathbf{4}$ & $\mathbf{5}$ \\
\hline Age (years) & 54 & 62 & 31 & 36 & 40 \\
Gender & Female & Male & Male & Male & Male \\
On admission SAPS II score & 54 & 64 & 54 & 38 & 52 \\
On admission SOFA score & 10 & 15 & 15 & 12 & 13 \\
Renal replacement therapy & Yes & Yes & Yes & Yes & Yes \\
Methylprednisolone & No & Yes & Yes & Yes & Yes \\
Hospital mortality & Alive & Alive & Alive & Alive & Alive \\
Time from CMV to HFOV (h) & $16(13.5)^{*}$ & 8 & $23(8)^{*}$ & 7.5 & $16.5(12)^{*}$ \\
Duration of MV (days) & 13.5 & 6.8 & 7.0 & 5.0 & 10.5 \\
Duration of HFOV (days) & 6.7 & 2 & 3.1 & 1.8 & 3.8 \\
Length of ICU stay (days) & 13.8 & 7.9 & 7.4 & 5.5 & 11.5 \\
Length of hospital stay (days) & 18.8 & 13.8 & 17.6 & 9.1 & 17.3 \\
\hline The
\end{tabular}

*The time was adjusted from admission to tertiary hospital and HFOV. SAPS II: Simplified Acute Physiological II; SOFA: Sequential Organ Failure Assessment; MV: Mechanical ventilation; HFOV: High frequency oscillatory ventilation; ICU: Intensive Care Unit; CMV: Conventional mechanical ventilation metabolic and respiratory acidosis and categorized as severe ARDS. Three patients had driving pressure (Plateau P - positive end-expiratory pressure [PEEP]) that was more than $15 \mathrm{mmHg}$, which in ARDS lungs are associated with increased mortality. ${ }^{[15]}$ They received high levels of PEEP, at the range of $12-20 \mathrm{cmH}_{2} \mathrm{O}$. After transition to HFOV, the median maximum mPaw was $34 \mathrm{cmH}_{2} \mathrm{O}$ (interquartile range [IQR] 31-37). The improvement of OI during the first $72 \mathrm{~h}$ is shown in Figure 1. Compared to the baseline values, there was a marked improvement in oxygenation as depicted by reduction in median OI at $72 \mathrm{~h}$. The median (IQR) of OI at baseline versus $72 \mathrm{~h}$ was 46.0 (37.9-53.3) versus 11.3 (11.2-15.6), with repeated measures ANOVA, $P<0.001$ and post hoc Tukey analysis, $P<0.005$. Figure 2 shows the boxplot of $\mathrm{PaO}_{2} / \mathrm{FiO}_{2}$ ratio (vs. time) of all patients before and during the first $72 \mathrm{~h}$ on HFOV. Significant improvement in median $\mathrm{PaO}_{2} / \mathrm{FiO}_{2}$ was observed as early as $24 \mathrm{~h}$ after commencement of HFOV. After 48 and $72 \mathrm{~h}$, the median value of $\mathrm{PaO}_{2} / \mathrm{FiO}_{2}$ ratio had improved significantly. The median (IQR) of $\mathrm{PaO}_{2} / \mathrm{FiO}_{2}$ ratio at baseline, 24,48 , and $72 \mathrm{~h}$ was 69.5 (56.3-84.6), 155.2 (114-280), 213 (184-388), and 232 (217-303), respectively, with repeated measures ANOVA, $P=0.002$ and post hoc Tukey analysis $P<0.005$. Figure 3 shows the $\mathrm{PaCO}_{2}$ values of all patients at Time 0 and during first $72 \mathrm{~h}$ of HFOV. The median (IQR) of $\mathrm{PaCO}_{2}$ at baseline, 24,48 , and $72 \mathrm{~h}$ was 51.9 (48.6-68.6), 42.5 (36.8-67.9), 48.5 (36.6-58.8), and 36.7 (31.9-55.0), respectively. No significant improvement in $\mathrm{PaCO}_{2}$ was observed within first $72 \mathrm{~h}(P=0.26)$. Table 5 demonstrated important hemodynamic data for all patients during the first $24 \mathrm{~h}$ of starting HFOV. The infusion rates for the vasoactive agents were the same as baseline or decreased after $4 \mathrm{~h}$ of initiation of therapy. Only two patients (number 3 and 5) received blood transfusion during treatment period.

\section{Discussion}

Pulmonary hemorrhage which may be sudden, unexpected, and massive may be the major cause of death in patients with leptospirosis. ${ }^{[16]}$ Our current case series suggested that the use of HFOV is not only safe but also able to rapidly improve oxygenation and ventilation. All patients had severe ARDS and responded rapidly

\begin{tabular}{|c|c|c|c|c|c|c|c|c|c|}
\hline Patient number & Plateau $\mathrm{P} \mathrm{cmH}_{2} \mathrm{O}$ & PEEP $\mathrm{cmH}_{2} \mathrm{O}$ & $\Delta \mathrm{P} \mathrm{cmH}_{2} \mathrm{O}$ & $\mathrm{FiO}_{2}$ & $\mathrm{pH}$ & $\mathrm{PaO}_{2} \mathrm{mmHg}$ & $\mathrm{PaCO}_{2} \mathrm{mmHg}$ & $\mathrm{PaO}_{2} / \mathrm{FiO}_{2} \mathrm{mmHg}$ & $\mathrm{HCO}_{3} \mathrm{mmol} / \mathrm{l}$ \\
\hline I & 30 & 16 & 14 & 0.9 & 6.99 & 76.1 & 68.6 & 84.6 & 11.9 \\
\hline 2 & 30 & 12 & 18 & 0.8 & 7.21 & 63.4 & 56.5 & 79.3 & 18.5 \\
\hline 3 & 30 & 12 & 18 & 1.0 & 7.13 & 56.3 & 51.9 & 56.3 & 14.7 \\
\hline 4 & 32 & 15 & 17 & 1.0 & 7.19 & 69.5 & 48.6 & 69.5 & I7. I \\
\hline 5 & 30 & 20 & 10 & 1.0 & 7.10 & 56 & 41.0 & 56 & 12.7 \\
\hline
\end{tabular}

$\triangle \mathrm{P}$ : Driving pressure (Plateau P-PEEP); PEEP: Positive end-expiratory pressure; Plateau P: Plateau pressure; $\mathrm{FiO}_{2}$ : Inspired oxygen fraction; $\mathrm{HCO}_{3}$ : Standard bicarbonate 


\begin{tabular}{|c|c|c|c|c|c|c|}
\hline $\begin{array}{l}\text { Patient } \\
\text { number }\end{array}$ & $\begin{array}{l}\text { Vasoactive agents prior } \\
\text { transition to HFOV (mcg/kg/ } \\
\text { min for NA and adrenaline) }\end{array}$ & $\begin{array}{l}\text { Vasoactive agents at } \\
4 \mathrm{~h} \mathrm{(mcg/kg/min} \mathrm{for} \\
\text { NA and adrenaline) }\end{array}$ & $\begin{array}{l}\text { Vasoactive agents at } \\
24 \mathrm{~h}(\mathrm{mcg} / \mathrm{kg} / \mathrm{min} \text { for } \\
\text { NA and adrenaline) }\end{array}$ & $\begin{array}{l}\text { Starting } \\
\text { mPaw } \\
\left(\mathrm{cmH}_{2} \mathrm{O}\right)\end{array}$ & $\begin{array}{l}\mathrm{mPaw} \\
\text { after } 24 \mathrm{~h} \\
\left(\mathrm{cmH}_{2} \mathrm{O}\right) \\
\end{array}$ & $\begin{array}{c}24 \text { h fluid balance } \\
\text { after starting } \\
\text { HFOV (ml) }\end{array}$ \\
\hline I & $\mathrm{NA}=0.8$ & $\mathrm{NA}=0.7 \mathrm{I}$ & $\mathrm{NA}=0.4$ & 32 & 30 & 2692 \\
\hline 2 & $N A=0.37$ & $N A=0.37$ & $\mathrm{NA}=0.27$ & 30 & 25 & 2060 \\
\hline 3 & $\mathrm{NA}=0.75$ & $N A=0.53$ & $N A=0.07$ & 34 & 32 & 2775 \\
\hline 4 & $\begin{array}{c}\mathrm{NA}=\mathrm{I} .24 \\
\text { Vasopressin }=\mathrm{I} .2 \mathrm{U} / \mathrm{h}\end{array}$ & $\begin{array}{c}\mathrm{NA}=0.44 \\
\text { Vasopressin }=0 \\
\text { (ceased after } 3 \mathrm{~h} \text { ) }\end{array}$ & $\mathrm{NA}=0($ ceased at $20 \mathrm{~h})$ & 33 & 28 & 1300.6 \\
\hline 5 & $\begin{array}{c}\mathrm{NA}=1.06 \\
\text { Adrenaline }=0.16 \\
\text { Vasopressin }=2 \mathrm{U} / \mathrm{h}\end{array}$ & $\begin{array}{c}\mathrm{NA}=0.48 \\
\text { Adrenaline }=0.14 \\
\text { Vasopressin }=0 \\
\text { (ceased after } 4 \mathrm{~h} \text { ) }\end{array}$ & $\begin{array}{c}\mathrm{NA}=0.56 \\
\text { Adrenaline }=0.14\end{array}$ & 35 & 27 & 3311 \\
\hline
\end{tabular}

NA: Noradrenaline; mPaw: Mean airway pressure; HFOV: High frequency oscillatory ventilation

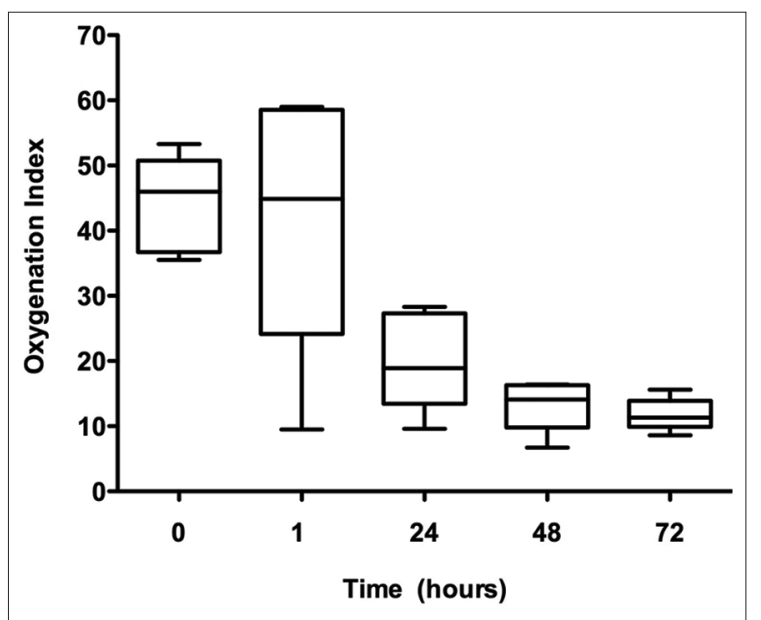

Figure I: Boxplot of oxygen index values (vs. time) of all patients before and during the first $72 \mathrm{~h}$ on high frequency oscillatory ventilation. Time 0 represents oxygen index on conventional mechanical ventilation before high frequency oscillatory ventilation. Repeated Measures analysis of variance, $P<0.000 \mathrm{I}$. Post hoc Tukey analysis with $P<0.005$ for $0 \mathrm{~h}$ versus $24 \mathrm{~h}, 0 \mathrm{~h}$ versus $48 \mathrm{~h}$, $0 \mathrm{~h}$ versus $72 \mathrm{~h}$, I versus $24 \mathrm{~h}, \mathrm{I} \mathrm{h}$ versus $48 \mathrm{~h}$, and I h versus $72 \mathrm{~h}$. Boxes show the median and interquartile range, whiskers show $10-90^{\text {th }}$ percentile

by showing improvements in $\mathrm{OI}$ and $\mathrm{PaO}_{2} / \mathrm{FiO}_{2}$ ratio within first $72 \mathrm{~h}$ of HFOV. In view of the rapid onset and extent of hemorrhage which may culminate quickly into asphyxiation and death, HFOV may indeed be lifesaving.

All patients had compatibleclinical data, epidemiological factors, and serological diagnosis of leptospirosis with modified Faine's criteria scores, part $(\mathrm{A}+\mathrm{B}+\mathrm{C})$ of more than 25 . They presented with an acute clinical course of fever, acute respiratory insufficiency, bilateral diffuse pulmonary infiltrates in chest radiographs [Figure 4], thrombocytopenia, septic shock, and mixed respiratory and metabolic acidosis. All patients developed AKI and required RRT. Total bilirubin levels were increased in four patients, associated with increased liver transaminases (alanine transaminase and aspartate transaminase) and creatine kinase. Previous reports have shown that the severity of pulmonary leptospirosis does not correlate with the presence of icterus. Besides, severe

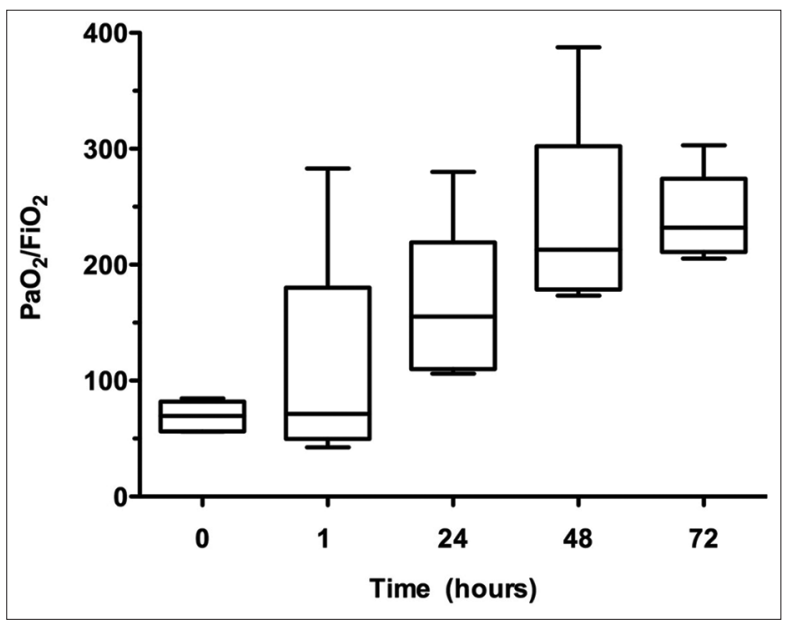

Figure 2: Boxplot of $\mathrm{PaO}_{2} / \mathrm{FiO}_{2}$ ratio (vs. time) of all patients before and during the first $72 \mathrm{~h}$ on high frequency oscillatory ventilation. Time 0 represents the $\mathrm{PaO}_{2} / \mathrm{FiO}_{2}$ on conventional mechanical ventilation before high frequency oscillatory ventilation. Repeated measures analysis of variance, $P=0.002$. Post hoc Tukey analysis with $P<0.0050 \mathrm{~h}$ versus $48 \mathrm{~h}, 0 \mathrm{~h}$ versus $72 \mathrm{~h}, \mathrm{I} \mathrm{h}$ versus $48 \mathrm{~h}$, and I h versus $72 \mathrm{~h}$. Boxes show the median and interquartile range, whiskers show $10-90^{\text {th }}$ percentile

pulmonary hemorrhage may occur in the icteric form or in the absence of jaundice. ${ }^{[16]}$ The evolution of LPHS is rapidly progressive, with acute gas exchange failure and asphyxia ensuing in just a few hours.

Leptospirosis is considered to be severe if a patient has acute febrile illness with complications. Empiric antibiotic therapy should be started as soon as clinical diagnosis is made without waiting for the confirmatory results of laboratory tests. In our practice, coinfection of leptospirosis can occur with malaria, dengue, viral hepatitis, and melioidosis. It is essential to investigate for these diseases even in patients who are confirmed to have leptospirosis. Severe leptospirosis can be treated with intravenous (IV) penicillin or ceftriaxone. Our patients received empirical IV meropenem which were later de-escalated to IV ceftriaxone $2 g$ daily for 7 days once diagnosis was confirmed by rapid tests. Severe leptospirosis may require correction of hypovolemia, 


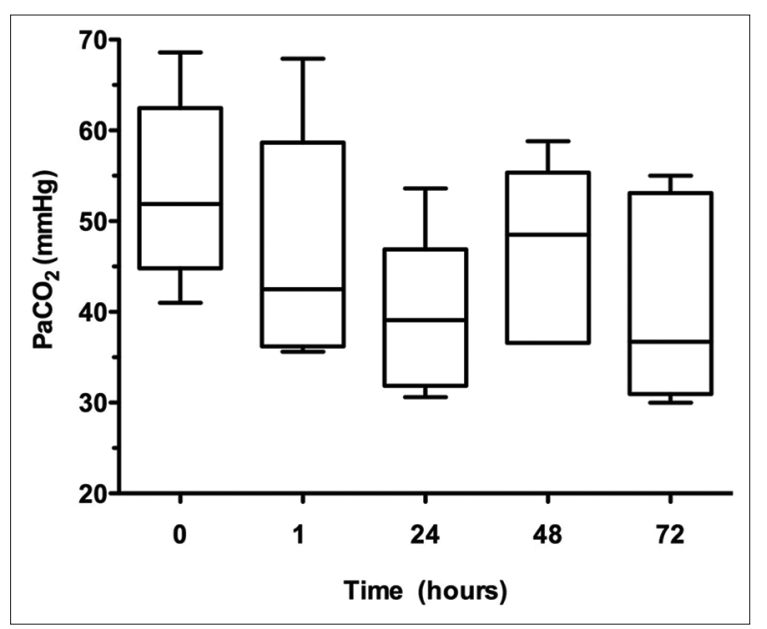

Figure 3: Boxplot of $\mathrm{PaCO}_{2}$ values (vs. time) of all patients before and during the first $72 \mathrm{~h}$ on high frequency oscillatory ventilation. Time 0 represents the $\mathrm{PaCO}_{2}$ on conventional mechanical ventilation just before high frequency oscillatory ventilation. Repeated measures analysis of variance, $P=0.26$. Boxes show the median and interquartile range, whiskers show $10-90^{\text {th }}$ percentile

shock, and electrolyte abnormalities. Transfusion of blood and blood products may be required to manage severe bleeding which is due to LPHS or associated thrombocytopenia and consumptive coagulopathy. RRT for AKI and early mechanical ventilation support for respiratory failure would definitely reduce mortality. ${ }^{[12]}$

Four of our patients received high dose of IV methylprednisolone. The increasing evidence that LPHS is immune-mediated has led to suggestion of outcome improvement through immunomodulation, for example, plasmapheresis, Ig, glucocorticoids, or cyclophosphamide. Several reports from India advocate the use of glucocorticoids in LPHS to reduce the need for ventilator support. ${ }^{[17]}$ The mortality benefit was not significant in cases where hemorrhage had already occurred and mechanical ventilation initiated. Corticosteroids would therefore be beneficial only if given within first $24 \mathrm{~h}$ of onset of pulmonary symptoms. The uses of plasma exchange and cyclophosphamide have been evaluated in patients with LPHS. ${ }^{[18]}$ However, concurrent removal of coagulation factors and consequent complications from dilutional coagulopathy and thrombocytopenia renders it unsuitable for these patients. Hypoxemia in LPHS may be difficult to treat despite maximal CMV given its rapid onset and extensive nature culminating into asphyxia and death. Arokianathan et al. have reported successful treatment of refractory hypoxemia with extracorporeal membrane oxygenation (ECMO) ${ }^{[19]}$ However, the use of HFOV in severe hypoxemia due to LPHS has not been extensively described in the literature.

ARDS may result in refractory and life-threatening hypoxemic respiratory failure. In severe cases, clinicians

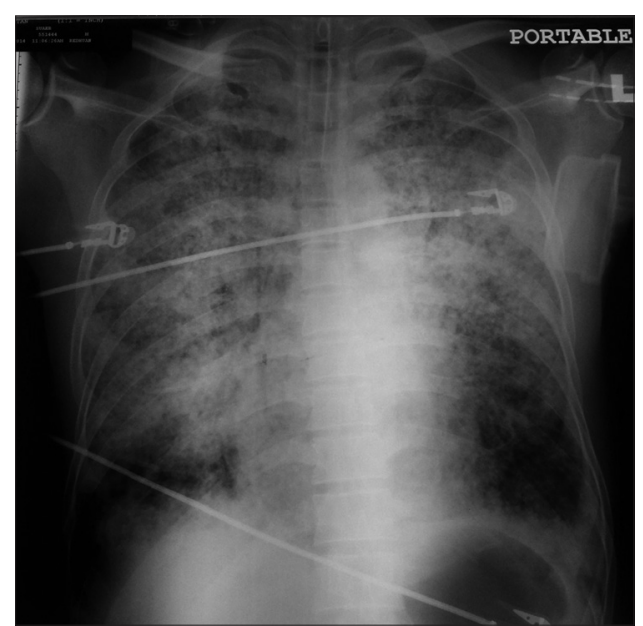

Figure 4: A chest $X$-ray of patient 4 with acute respiratory failure secondary to pulmonary hemorrhage and acute respiratory distress syndrome

commonly utilize interventions termed "hypoxemic rescue therapies" in an attempt to improve oxygenation. ${ }^{[20]}$ Without these therapies, CMV is associated with high mortality. The ICU physicians may make a transition to rescue therapies such as HFOV or ECMO when both these modalities are at their disposal. The results of the recently published OSCILLATE and OSCAR trials that compared HFOV and lung protective strategy will likely discourage the routine use of HFOV in ARDS. ${ }^{[21,22]}$ In these studies, many factors influence the outcome. Majority of the ICUs participating in the studies were new and inexperienced in HFOV. In the OSCILLATE trial, the HFOV group required higher vasopressor, more positive fluid balance and were more heavily sedated as compared to control group. Aggressive HFOV strategy may create significant hemodynamic instability due to the effect of very high intrathoracic pressure on the right ventricular afterload. A more positive fluid balance in the HFOV group would also be detrimental and affect mortality. Patient selection may be an important factor. In ARDS patients with heterogenous and nonrecruitable lung, the associated increased mPaw in HFOV may lead to overdistension of healthy lung regions without increased in aeration of collapsed alveoli.

However, HFOV may still have a role in selected groups of patients such as in pulmonary hemorrhage. In the current study, all patients required rescue therapy within $24 \mathrm{~h}$ of CMV initiation. HFOV uses high continuous distending mPaw to achieve lung recruitment and improve oxygenation. Such pressures tamponade the transudation of hemorrhagic edema and decrease blood flow from ruptured capillaries by increasing intrathoracic pressure and reducing pulmonary blood flow. ${ }^{[23]}$ Furthermore, continuous high pressure will result in fewer pressure swings during the respiratory cycle thus 
minimize alveolar bleeding. All the above mechanisms will reduce the acute extrusion of hemorrhagic fluid from injured capillaries as the result of toxin-mediated vasculitis. Duval et al. described the safety and efficacy of HFOV as rescue therapy for lung hemorrhage in a retrospective case study of nine children. HFOV was started when conventional ventilation was ineffective in controlling hemorrhage resulting in hypoxemia and hypercarbia. They reported treatment benefit in seven infants and mortality in two. ${ }^{[23]} \mathrm{A}$ few factors may have contributed to the success of HFOV in our cohorts. Other than the possible mechanisms explained above, we noted that we were able to wean the vasoactive agents within $24 \mathrm{~h}$ of initiation of HFOV. We included cautious recruitment maneuver in our protocol. Aggressive volume resuscitation before transition to HFOV was paramount in achieving optimal hemodynamic goals during the first few hours of therapy. To the best of our knowledge, this is the first case study demonstrating the effectiveness and safety of HFOV intervention in adult patients with acute refractory hypoxemic respiratory failure due to LPHS.

\section{Conclusion}

Hypoxemia in LPHS is a challenging clinical scenario not usually responsive to maximal support on CMV. Our case study demonstrated that in such patients, HFOV was a safe and effective rescue therapy with a good outcome. This intervention may indeed be lifesaving in an otherwise rapid, overwhelming, and potentially fatal form of pulmonary hemorrhage.

\section{Financial support and sponsorship Nil.}

\section{Conflicts of interest}

There are no conflicts of interest.

\section{References}

1. Marchiori E, Lourenço S, Setúbal S, Zanetti G, Gasparetto TD, Hochhegger B. Clinical and imaging manifestations of hemorrhagic pulmonary leptospirosis: A state-of-the-art review. Lung 2011;189:1-9.

2. Bharti AR, Nally JE, Ricaldi JN, Matthias MA, Diaz MM, Lovett MA, et al. Leptospirosis: A zoonotic disease of global importance. Lancet Infect Dis 2003;3:757-71

3. Gulati S, Gulati A. Pulmonary manifestations of leptospirosis. Lung India 2012;29:347-53.

4. Bethlem EP, Carvalho CR. Pulmonary leptospirosis. Curr Opin Pulm Med 2000;6:436-41.
5. Costa F, Hagan JE, Calcagno J, Kane M, Torgerson P, Martinez-Silveira MS, et al. Global morbidity and mortality of leptospirosis: A systematic review. PLoS Negl Trop Dis 2015;9:e0003898.

6. Segura ER, Ganoza CA, Campos K, Ricaldi JN, Torres S, Silva H, et al. Clinical spectrum of pulmonary involvement in leptospirosis in a region of endemicity, with quantification of leptospiral burden. Clin Infect Dis 2005;40:343-51.

7. Yersin C, Bovet P, Mérien F, Clément J, Laille M, Van Ranst M, et al. Pulmonary haemorrhage as a predominant cause of death in leptospirosis in Seychelles. Trans R Soc Trop Med Hyg 2000;94:71-6.

8. Ministry of Health Malaysia. Guidelines for the diagnosis, management, prevention and control of leptospirosis in Malaysia. 2011. p. 41.

9. Dolhnikoff M, Mauad T, Bethlem EP, Carvalho CR. Pathology and pathophysiology of pulmonary manifestations in leptospirosis. Braz $\mathrm{J}$ Infect Dis 2007;11:142-8.

10. Croda J, Neto AN, Brasil RA, Pagliari C, Nicodemo AC, Duarte MI. Leptospirosis pulmonary haemorrhage syndrome is associated with linear deposition of immunoglobulin and complement on the alveolar surface. Clin Microbiol Infect 2010;16:593-9.

11. De Brito T, Aiello VD, da Silva LF, Gonçalves da Silva AM, Ferreira da Silva WL, Castelli JB, et al. Human hemorrhagic pulmonary leptospirosis: Pathological findings and pathophysiological correlations. PLoS One 2013;8:e71743.

12. Kumar S. Indian guidelines for the diagnosis and management of human leptospirosis. Mortality 2012;5:23-9.

13. Vieira SR, Brauner JS. Leptospirosis as a cause of acute respiratory failure: Clinical features and outcome in 35 critical care patients. Braz J Infect Dis 2002;6:135-9.

14. Fessler HE, Derdak S, Ferguson ND, Hager DN, Kacmarek RM, Thompson BT, et al. A protocol for high-frequency oscillatory ventilation in adults: Results from a roundtable discussion. Crit Care Med 2007;35:1649-54.

15. Amato MB, Meade MO, Slutsky AS, Brochard L, Costa EL, Schoenfeld DA, et al. Driving pressure and survival in the acute respiratory distress syndrome. N Engl J Med 2015;372:747-55.

16. Assimakopoulos SF, Fligou F, Marangos M, Zotou A, Psilopanagioti A, Filos KS. Anicteric leptospirosis-associated severe pulmonary hemorrhagic syndrome: A case series study. Am J Med Sci 2012;344:326-9.

17. Shenoy VV, Nagar VS, Chowdhury AA, Bhalgat PS, Juvale NI. Pulmonary leptospirosis: An excellent response to bolus methylprednisolone. Postgrad Med J 2006;82:602-6.

18. Trivedi SV, Vasava AH, Bhatia LC, Patel TC, Patel NK, Patel NT. Plasma exchange with immunosuppression in pulmonary alveolar haemorrhage due to leptospirosis. Indian J Med Res 2010;131:429-33.

19. Arokianathan D, Trower K, Pooboni S, Sosnowski A, Moss P, Thaker H. Leptospirosis: A case report of a patient with pulmonary haemorrhage successfully managed with extra corporeal membrane oxygenation. J Infect 2005;50:158-62.

20. Hodgson C, Carteaux G, Tuxen DV, Davies AR, Pellegrino V, Capellier G, et al. Hypoxaemic rescue therapies in acute respiratory distress syndrome: Why, when, what and which one? Injury 2013;44:1700-9.

21. Ferguson ND, Cook DJ, Guyatt GH, Mehta S, Hand L, Austin P, et al. High-frequency oscillation in early acute respiratory distress syndrome. N Engl J Med 2013;368:795-805.

22. Young D, Lamb SE, Shah S, MacKenzie I, Tunnicliffe W, Lall R, et al. High-frequency oscillation for acute respiratory distress syndrome. N Engl J Med 2013;368:806-13.

23. Duval EL, Markhorst DG, Ramet J, van Vught AJ. High-frequency oscillatory ventilation in severe lung haemorrhage: A case study of three centres. Respir Med CME 2009;2:92-8. 